\title{
Optimization of Tribological Properties of Nonasbestos Brake Pad Material by Using Steel Wool
}

\author{
R. Vijay, ${ }^{1}$ M. Jees Janesh,, ${ }^{1}$ M. A. Saibalaji, ${ }^{1}$ and V. Thiyagarajan ${ }^{2}$ \\ ${ }^{1}$ GKM College of Engineering and Technology, Chennai, Tamil Nadu 600063, India \\ ${ }^{2}$ Sree Sastha Institute of Engineering and Technology, Chennai, Tamil Nadu 600123, India \\ Correspondence should be addressed to R. Vijay; vimyr2010@gmail.com
}

Received 26 May 2013; Accepted 29 August 2013

Academic Editor: Huseyin Çimenoğlu

Copyright (c) 2013 R. Vijay et al. This is an open access article distributed under the Creative Commons Attribution License, which permits unrestricted use, distribution, and reproduction in any medium, provided the original work is properly cited.

\begin{abstract}
The gradual phasing out of typical brake pad material led to the spark of extensive research in development of alternatives. Henceforth we have performed a tribological study to improve the performance characteristics of the friction product (brake pad) by using steel wool, a metallic material which has an excellent structural reinforcement property and high thermal stability which are indeed required to improve the performance of the brake pad. Under the study, five frictional composites were developed and optimized using the same ingredients in an appropriate proportion except steel wool $(0 \%, 4 \%, 8 \%, 12 \%$, and $16 \%)$ which is compensated by synthetic barite, and the synthesized compositions are designated as $\mathrm{Na} 01$ to $\mathrm{Na} 05$. The developed pads are tested for tribological behaviour under conventional environment in a standard pin on disc tribometer. It is observed that increase in steel wool concentration resulted in high coefficient of friction and low wear rate of pad as resulted in Na05 composition. SEM analysis of the wear surface has proved to be useful in understanding the wear behaviour of the composites.
\end{abstract}

\section{Introduction}

The core of the braking device is friction material, which is expected to continue its functioning reliably and efficiently for a prolonged time in adverse operating conditions [1]. Nonasbestos organic fiber reinforced metallic friction composites are increasingly being used in automotive brake disc pads, shoes, linings, blocks, clutch facings, and so forth, primarily because of awareness of health hazards of asbestos. These are essentially multi ingredient systems in order to achieve the desired amalgam of performance properties [2$5]$, and more than several hundred ingredients have been reported in the literature for being used to tailor the friction composites. These are classified into four major categories, namely, binder, structural modifiers, friction modifiers, and fillers, based on the major function they perform apart from controlling friction and wear performance.

The influence of these ingredients on performance properties is so complex that formulation of friction materials is still referred as an art rather than science [2]. These friction materials have to satisfy safety-related features such as friction stability, resistance to fade, and ecofriendly nature.
Nowadays, factors such as economics of operation, increased power to weight ratio, road development, and road traffic demand more efficient braking system which requires improved brake friction materials [6].

The use of asbestos fiber as reinforcement in the friction materials started in the beginning of the 20th century. Since asbestos fiber met major requirements of brake friction material, asbestos based friction composites became popular all over the world. Later on, medical reports regarding asbestos exposure to humans proved that asbestos is carcinogenic and can cause deadly diseases. It resulted in ban of asbestos based friction materials in the developed countries, and many developing countries are now on the same path. This motivated researchers all over the world to find safe replacement for asbestos fibers. Glass, steel, aramid, carbon fibers, ceramic, and so forth are used solely or in cocktail in nonasbestos organic (NAO) friction formulations, and research is continuing for more improved friction materials [7-9].

Barite is widely used as inert filler [10]. It is found that the presence of steel wool increases load bearing capacity and 
TABLE 1: Steel wool chemical composition and properties.

\begin{tabular}{llcc}
\hline S. no. & Description & Unit & Grade GMT-180 \\
\hline \multirow{3}{*}{1} & Chemical Composition & $\%$ & \\
& Carbon & $\%$ & $0.08-0.13$ \\
& Manganese & $\%$ & $0.81-0.96$ \\
& Silicon & $\%$ & $0.04 \mathrm{Max}$ \\
& Phosphorus & $\%$ & $0.05-0.08$ \\
& Sulphur & $\%$ & $0.03 \mathrm{Max}$ \\
2 & Raw materials wire & $\mathrm{mm}$ & $2.81-2.92$ \\
3 & diameter & $\mathrm{Kg} / \mathrm{mm}^{2}$ & $90-130$ \\
4 & Tensile strength & $\%$ & $0.15 \mathrm{Max}$ \\
5 & Acetone extraction & $\mathrm{Gm} / \mathrm{cc}$ & $0.83-1.15$ \\
6 & Apparent density & - & $7.5-7.95$ \\
\hline
\end{tabular}

thermal stability and reduced the wear rate, high coefficient of friction, and temperature rise. So the steel wool and the barites are varied in a complementary manner, and the pads are synthesized, and they are tested for their tribological properties using pin on disc condition under normal room condition. SEM analysis is carried out for the worn out pad samples. SEM images of steel wool and barite are shown in Figures 1 and 2.

The Specification and Properties of the Steel wool used in this sample preparation are given in the Table 1.

\section{Experimental}

2.1. Formulation of Samples. The fabrication of composites containing twelve ingredients was based on keeping parent composition of 10 ingredients (around $68 \mathrm{wt} . \%$ ) constant and varying two ingredients, namely steel wool and barite (around $32 \mathrm{wt} . \%$ ) in complementary manner as shown in Table 2 based on a systematic increase in steel wool (0, $4,8,12$, and 16 wt.\%). The parent composition contained copper fiber, antimony trioxide, alkyl benzene phenolic resin, zirconium silicate synthetic graphite, NBR, friction dust, calcium carbonate, molybdenum disulphide, and vermiculite. The ingredients were mixed in a drum mixing machine to ensure the macroscopic homogeneity using a chopper speed of $3000 \mathrm{rpm}$ and feeder speed of $150 \mathrm{rpm}$. The mixing machine is shown in Figure 3. First, the steel wool fiber and copper fibers were churned together for 6 minutes in a drum mixer. Feeder and chopper both were switched on at $120 \mathrm{rpm}$. Calcium carbonate, molybdenum disulphide, and synthetic graphite were added and mixed for 16 minutes. Then straight phenolic resin was added and the mixer was run for 5 minutes. Finally, antimony trioxide and NBR rubber were added, and the mixer was run for 4 minutes. The mixing sequence and time of mixing of each lot of ingredients led to proper uniformity in the mixture. If mixing time is low, proper homogeneity cannot be achieved. If it is too high, it does not improve the homogeneity further. Hence, it has to be optimized earlier. The mixture was then placed into a sixcavity mould supported by the adhesive-coated back plates.

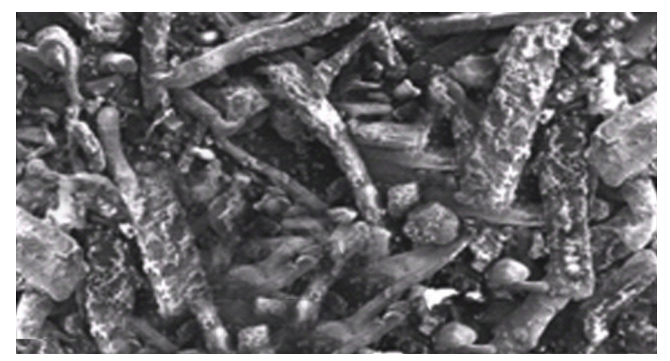

$10 \mu \mathrm{m} \mathrm{EHT}=10.00 \mathrm{~W}$ Signal A $=$ SW 1 Date: 20 Jul 2012

$\longmapsto \quad$ WD $=9.5 \mathrm{~mm} \quad$ Mag $=500 \mathrm{x} \quad$ Time: $10: 12$

FIGURE 1: SEM image of steel wool at 500x magnification.

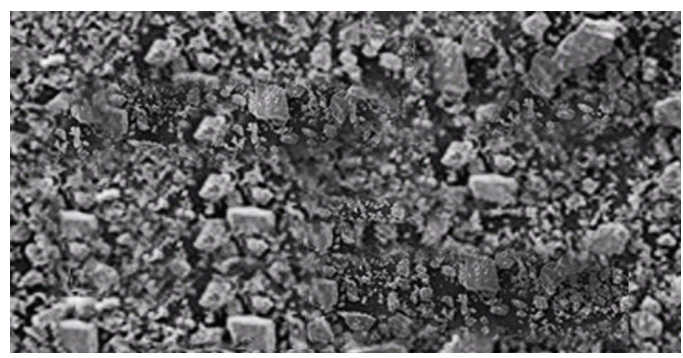

$10 \mu \mathrm{m} \quad \mathrm{EHT}=10.00 \mathrm{~W} \quad$ Signal A $=$ NA01 Date: $20 \mathrm{Jul} 2012$

$\mapsto \quad W D=9.5 \mathrm{~mm} \quad \mathrm{Mag}=500 \mathrm{x} \quad$ Time: 09:12

FIGURE 2: SEM image of barite at 500x magnification.

Each cavity was filled with approximately $80 \mathrm{~g}$ of the mixture and heat cured in a compression-moulding machine under a pressure of 17-21 MPa for 8-9 min at curing temperature, that is, between 130 and $150^{\circ} \mathrm{C}$. Five intermittent "breathings" were also allowed during the initiation of curing to expel volatiles and gases. The curing machine with 6 cavities is shown in Figure 4 . The pads were then removed and were postcured in an oven at around $130^{\circ} \mathrm{C}$ for $8 \mathrm{hr}$. The postcuring operation is done to cure the residual resin. As per standard practice in the literature after optimization, it is done at $130^{\circ} \mathrm{C}$ for $8 \mathrm{hr}$ to ensure complete curing of the resin [11]. The post curing apparatus is shown in Figure 5. The surfaces of the pads were then polished with a grinding wheel to attain the desired thickness and smooth surface. The finished pad is shown in Figure 6.

\section{Thermogravimetric Analysis of Developed Frictional Composites}

Thermogravimetric analysis of the developed composites is carried out in a DTG 60 series type machine using alumina pans $(6.04 \mathrm{mg})$, under zero-air atmosphere $(50 \mathrm{~mL} / \mathrm{min})$ at a heating rate of $10^{\circ} \mathrm{C} / \mathrm{min}$.

Figure 7 shows thermo-gravimetric analysis (TGA) results of the developed friction composites which reveals the weight loss $\%$ when exposed to $50-800^{\circ} \mathrm{C}$. The weight loss \% of NA05 during exposure was $16.93 \%$. For NA04 it was $17.558 \%$, for NA03 it was $19.02 \%$, for NA02 it was $20.57 \%$, and for NA01 the loss was $22.38 \%$. Hence NA05 has better thermal stability than the other composites. Hence we can 
TABLE 2: List of the ingredients in composites by weight percentage.

\begin{tabular}{|c|c|c|c|c|c|c|}
\hline S. no. & Ingredients & $\mathrm{Na} 01$ & $\mathrm{Na} 02$ & $\mathrm{Na} 03$ & $\mathrm{Na} 04$ & $\mathrm{Na} 05$ \\
\hline 1 & Steel wool $^{*}$ & $\mathbf{0}$ & 4 & 8 & 12 & 16 \\
\hline 2 & Copper fiber & 5 & 5 & 5 & 5 & 5 \\
\hline 3 & Antimony trioxide & 1.5 & 1.5 & 1.5 & 1.5 & 1.5 \\
\hline 4 & Alkyl benzene phenolic resin & 11 & 11 & 11 & 11 & 11 \\
\hline 5 & NBR rubber & 3 & 3 & 3 & 3 & 3 \\
\hline 6 & Synthetic graphite & 10 & 10 & 10 & 10 & 10 \\
\hline 7 & Molybdenum disulphide & 2 & 2 & 2 & 2 & 2 \\
\hline 8 & Zirconium silicate & 2 & 2 & 2 & 2 & 2 \\
\hline 9 & Friction dust & 12 & 12 & 12 & 12 & 12 \\
\hline 10 & Synthetic barites* & 32 & 28 & 24 & 20 & 16 \\
\hline 11 & Vermiculite & 7 & 7 & 7 & 7 & 7 \\
\hline \multirow[t]{2}{*}{12} & Calcium carbonate & 14.5 & 14.5 & 14.5 & 14.5 & 14.5 \\
\hline & Total & 100 & 100 & 100 & 100 & 100 \\
\hline
\end{tabular}

* bold font refers to varying composition (i.e. 2 varying ingredients in the base composition).

TABLE 3: List of various physical, thermal, and mechanical characterization.

\begin{tabular}{|c|c|c|c|c|c|c|}
\hline S. no. & Properties & $\mathrm{Na} 01$ & $\mathrm{Na} 02$ & $\mathrm{Na} 03$ & $\mathrm{Na} 04$ & $\mathrm{Na} 05$ \\
\hline 1 & Specific gravity & 2.23 & 2.41 & 2.61 & 2.74 & 2.92 \\
\hline 2 & Hardness HRS & 70 & 78 & 84 & 91 & 97 \\
\hline 3 & Acetone extract (\%) & 2.18 & 2.15 & 2.11 & 2.08 & 2.02 \\
\hline 4 & Heat swell (mm) & 0.5 & 0.7 & 0.9 & 0.12 & 0.15 \\
\hline 5 & Loss of ignition at $800^{\circ} \mathrm{C}(\%)$ & 24.54 & 22.33 & 20.21 & 18.51 & 16.47 \\
\hline 6 & Cold shear $\left(\mathrm{Kg} / \mathrm{cm}^{2}\right)$ & 48 & 46 & 45 & 42 & 39 \\
\hline 7 & Tensile strength $(\mathrm{MPa})$ & 37.21 & 36.21 & 33.41 & 32.45 & 30.416 \\
\hline 8 & Compressive strength $(\mathrm{MPa})$ & 119.67 & 125.56 & 133.42 & 145.50 & 174.80 \\
\hline
\end{tabular}

observe that the higher the steel fiber content, the higher the thermal stability.

\section{Physical, Thermal, and Mechanical Characterization}

Based on the IS2742 standards of 1994 the following properties are done and tabulated in Table 3.

As seen from Table 3, the higher the steel wool content, the higher the specific gravity, compressive strength, and hardness. The lesser value of the loss of ignition indicates the resistance to thermal degradation. Hence $\mathrm{Na} 05$ which has the higher steel wool content has good thermal stability. Also, the acetone extract value of $\mathrm{Na} 05$ is comparatively better than that of the other composites. Here the tensile strength is lesser for higher steel wool content.

\section{Test Setup and Procedure for Friction and Wear by Pin on Disc Testing}

Friction tests were performed on friction coefficient test rig as per ASTM G 99-95a standards (E D201 Series make). It is fully computerized and is programmable to study friction reaction against speed, load, temperature, and wear. New rotor discs and brake pad composite samples were used for each test. Each composition was tested at least twice on the test rig to develop confidence in the data. The rig uses pearlitic gray cast iron discs (diameter of $180 \mathrm{~mm}$, thickness of $38 \mathrm{~mm}$ ) and a brake pad test sample in the form of pin of $8 \mathrm{~mm}$ diameter $\times 60 \mathrm{~mm}$ length (Figure 8 ). Each test sample was mounted on the load arm and pressed against the rotating disc. The rotating cast iron disk has a constant sliding speed of $1500 \mathrm{rpm}$ and the test duration was $80 \mathrm{~min}$. The surfaces of the samples and the cast iron discs had to be grounded with 320-grid sandpaper before beginning the test. The normal load was varied up to $147.15 \mathrm{~N}$ to achieve a constant friction force. The friction coefficient was calculated by measuring normal and shear forces every $5 \mathrm{~s}$ over the entire duration of the test. The weight and thickness of the samples were noted before and after the friction test to calculate the total wear of each sample. An infrared sensor was used to record the temperature of the contact interface during the test and readings were recorded every second. The apparatus of pin on disc is shown in Figure 9.

5.1. Friction and Wear Characteristics of Various Composites. The results of various composites named $\mathrm{Na} 01-\mathrm{Na} 05$ are shown below in the graphs. The test has taken place at a load of $98.1 \mathrm{~N}$ at $1500 \mathrm{rpm}$. The tests were taken for time versus coefficient of friction and time versus wear. The interface temperature is noted, and the initial and final weights are weighed.

The weight loss was determined from the corresponding measurements of the samples done before and after the wear 


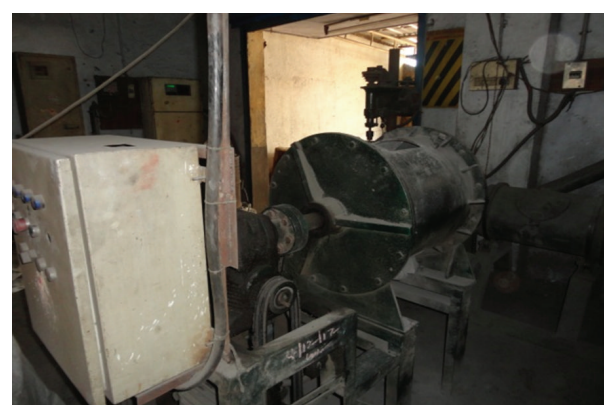

Figure 3: Mixing machine.

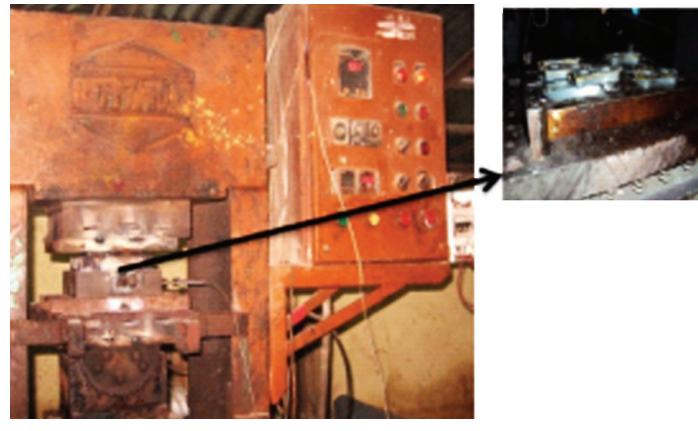

FIGURE 4: Curing apparatus.

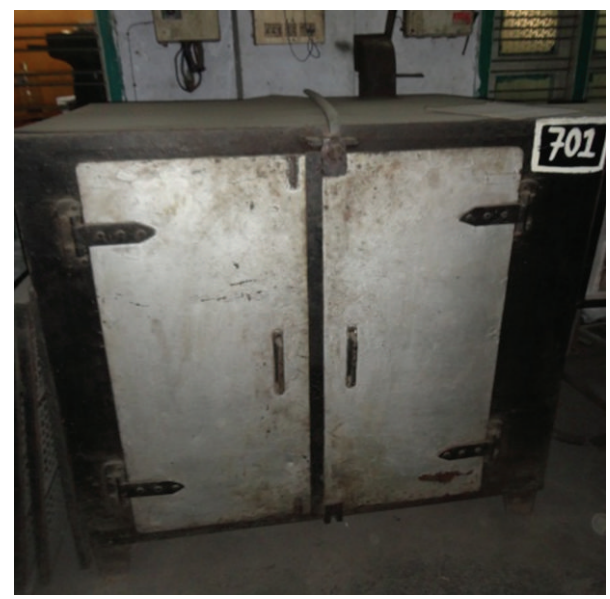

FIGURE 5: Postcuring apparatus.

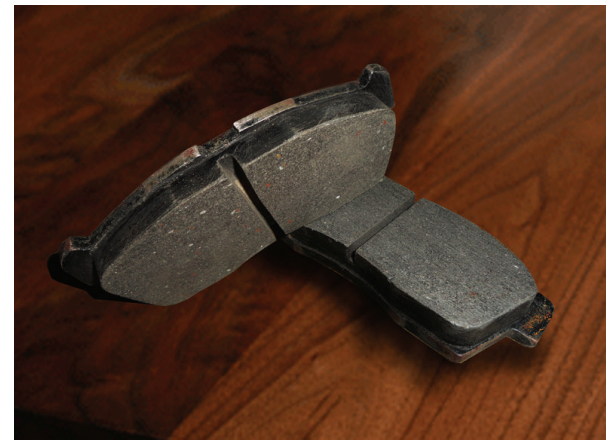

FIGURE 6: Finished brake pad.

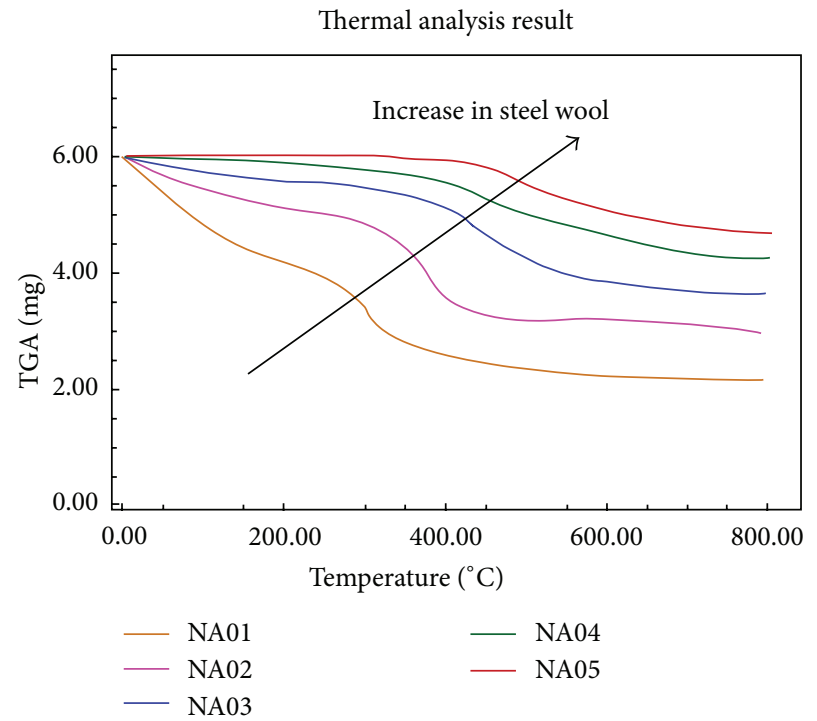

FIGURE 7: Thermogravimetric analysis (TGA) results of the developed friction composites.



Figure 8: Pin for testing.

test. The specific wear rate $W_{s}$ was calculated according to the following equation:

$$
W_{s}=\frac{\Delta m}{L \rho F_{n}\left[\mathrm{~mm}^{3} / \mathrm{Nm}\right]},
$$

where $\Delta m$ is the sample's mass loss, $L$ is the total sliding distance and $\rho$ is the density of the sample during sliding. 


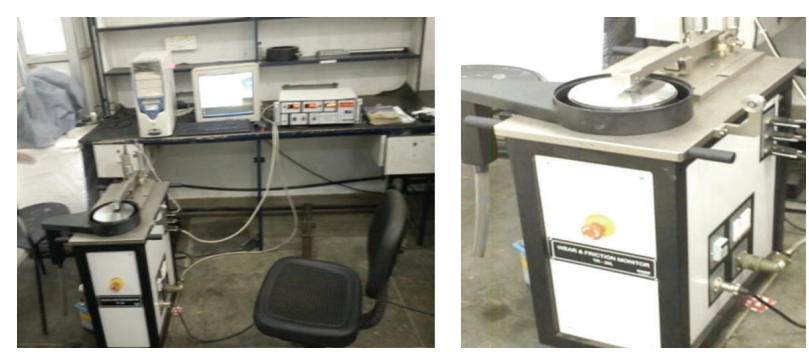

FIGURE 9: Pin on disc apparatus.

The wear resistance of the material is the inverse of the specific wear rate.

The contact area variations are corresponded by different processes of friction coefficient variations. It can be stated that the friction generally increases with an increased area of real contact. However, the distribution of load over the different phases will also affect the friction level. The initial runningin of a new disc is associated with a slow increase of the coefficient of friction. The as-manufactured disc surface has a spiral ridge pattern resulting from the turning operation. During the first few minutes, this ridge is gradually worn off, resulting in a much smoother surface. Correspondingly, the coefficient of friction against the pin increases. The increase in steel wool led to more efficient dissipation of frictional heat. The higher the dissipation, the lower the surface temperature and hence the lower the degradation of the organic components in the composites, which hence helped to maintain consistent friction level.

From Figure 10, the $\mu$ value of NA05 goes as high as 0.504 which is attributed to the good thermal stability caused due to lesser amount of weight loss as found from the loss of ignition test. From the Figure 11 the wear rate can be visualized. The work of the steel wool in brake composite does not only provide high and stable friction coefficient, but also strengthens composite body. More content of steel wool in the brake composite NA05 causes more fibers to appear on the friction surface. This made the true contact area between the fibers and brake disk increase, so a higher friction coefficient is achieved [12].

5.2. Wear of the Compositions. Wear (loss by weight \%) is as follows: $\mathrm{Na} 05<\mathrm{Na} 04<\mathrm{Na} 03<\mathrm{Na} 02<\mathrm{Na} 01$.

The graphical representation is shown in Figure 12.

5.3. Worn Surface Studies by SEM. Scanning electron micrographs (SEM-5000 type having up to $1 \mathrm{~nm}$ and electron gun tungsten type) of worn surfaces are shown in Figures 13(a), 13(b), 13(c), 13(d) and 13(e), and are arranged in the sequence of increasing wear resistance. During testing, the pin surface is in continuous contact against the disc, while each part of the disc surface experiences intermittent contact. As for all dry sliding systems, the friction force is transmitted via the area of real contact. This area of real contact is confined within a number of contact plateaus, over the pin surface. The pins made with varying loading level of steel wool show different wear properties. Steel wool has a relatively high resistance to sliding wear against the disc. Thus, following a short runningin, the metal fibres will stand slightly higher than less wear resistant constituents, forming the central part of the contact plateaus. During steady state wear, the more wear resistant constituents will carry a large proportion of the load and will in this way protect the adjacent material. The higher proportion of the load carrying will subsequently lead to the wear resistant components having a higher influence on the coefficient of friction. Therefore, despite softer components filling the majority of the lining volume, the contact situation is dominated by metal to metal contact with respect to both friction and wear. The topography composed of flat contact plateaus rising over irregular surroundings. When the micrographs are compared, extent of secondary and primary plateaus was the lowest and highest, respectively, in $\mathrm{Na} 05$, supporting its best wear behavior. In case of $\mathrm{Na} 01$, the situation was exactly the reverse supporting its poorest wear performance. For $\mathrm{Na} 02$, $\mathrm{Na} 03$, and $\mathrm{Na} 04$, which showed moderate wear behavior, the surface topography supported this since it showed moderate size and number of secondary plateaus.

\section{Conclusions}

Based on the friction and wear tests and other properties tests on the brake pad the following results are obtained.

(i) Steel wool increased the hardness due to its high density and decreased the thermal degradation as found by loss of ignition and TGA.

(ii) The higher the steel wool content, the better the friction performance in the pin on disc test procedure.

(iii) Wear also showed the same pattern.

(iv) SEM studies specify the tendency of primary and secondary plateaus formation which was maximum with high steel wool content $\mathrm{Na05}$ composition.

(v) Hence, it is concluded that composite NA05 is more efficient than other compositions since it has good coefficient of friction with less wear rate.

(vi) However, the wear on the mating part, namely, the rotor has to be checked for the implementation of this formulation in real time application. 


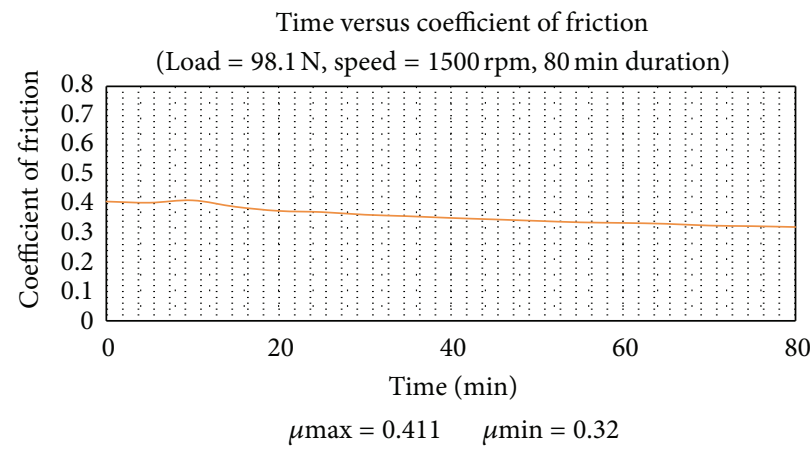

(a)

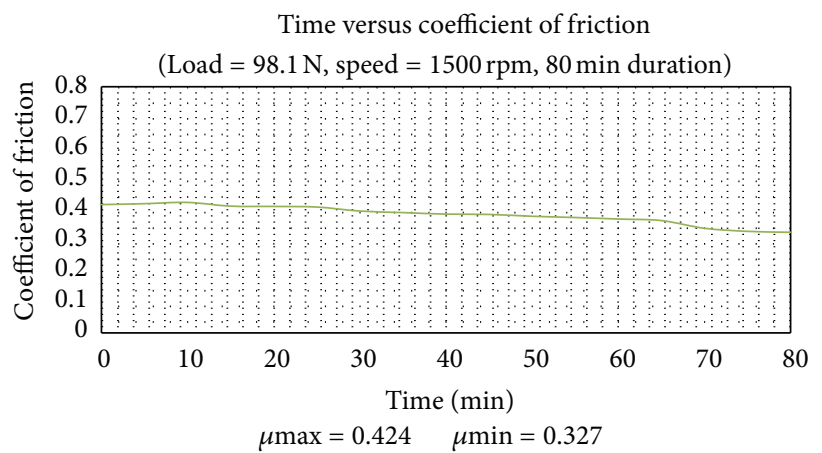

(c)



(b)

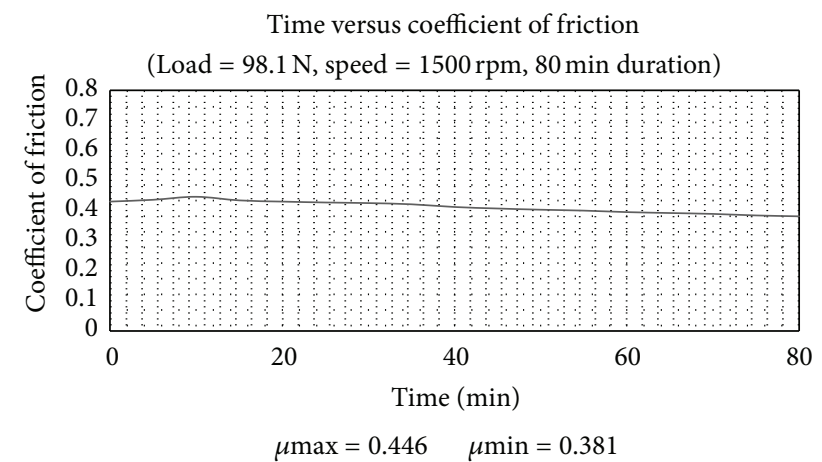

(d)

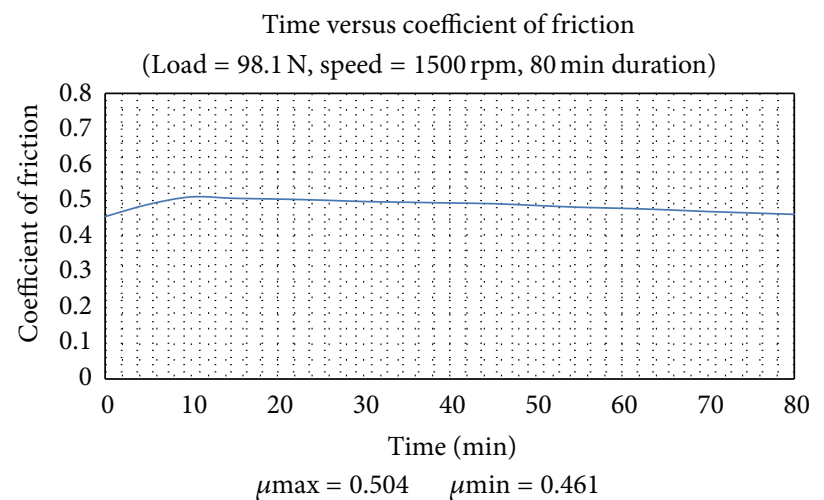

(e)

Figure 10: (a) Time versus $\mu$ for Na01. (b) Time versus $\mu$ for Na02. (c) Time versus $\mu$ for Na03. (d) Time versus $\mu$ for Na04. (e) Time versus $\mu$ for $\mathrm{Na} 05$.

\section{Appendix}

(1) Specific Gravity Calculation. The prepared sample is suspended in air using thread and then weighed. Then the weighed sample is immersed in water for 3 minutes. To prevent the bubble formation on the surface, detergent (one part in 10000) is added to water and weighed:

$$
\text { Specific Gravity }=\left[\frac{W_{A}}{W_{A}-W_{B}}\right] \text {, }
$$

where $W_{A}=$ weight in air in grams and $W_{B}=$ weight in water in grams.
(2) Heat Swell Calculation. Heat swelling was measured by SAE J 160 JNU80 standard. Thickness of the sample $(10 \mathrm{~mm} \times$ $10 \mathrm{~mm} \times 4 \mathrm{~mm}$ ) from the brake pad at six different places was measured accurately at room temperature. The process was repeated after heating the sample in oven at $200 \pm 2^{\circ} \mathrm{C}$ for $2 \mathrm{hrs}$. The increase in thickness was recorded as heat swell and percentage was calculated.

(3) Measurement of Shear Strength. The value for Shear Strength is found out using the following procedure.

(a) Place the specimen in the fixture and gradually increase the load in direction parallel to the direction of stress at normal service conditions. 


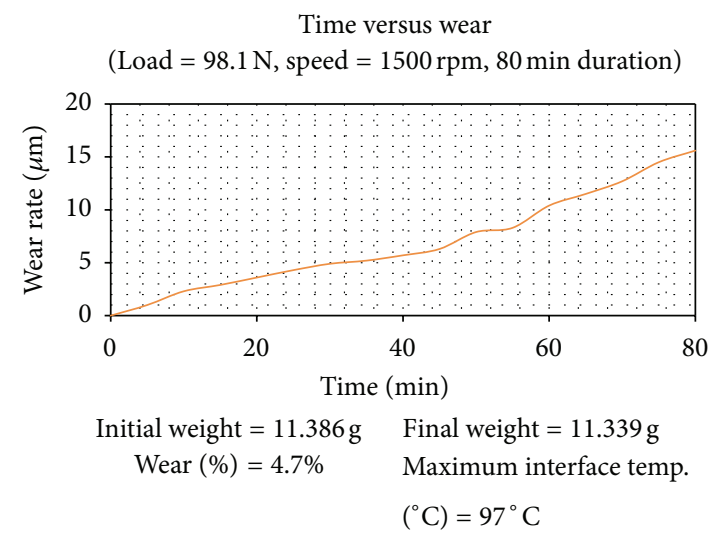

(a)

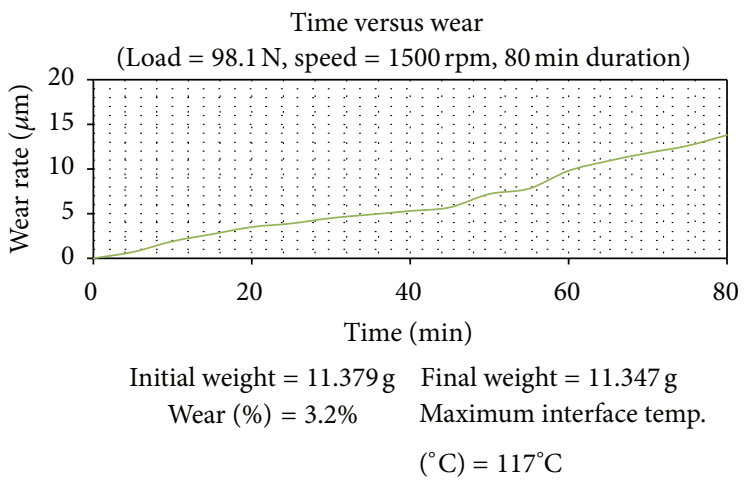

(c)

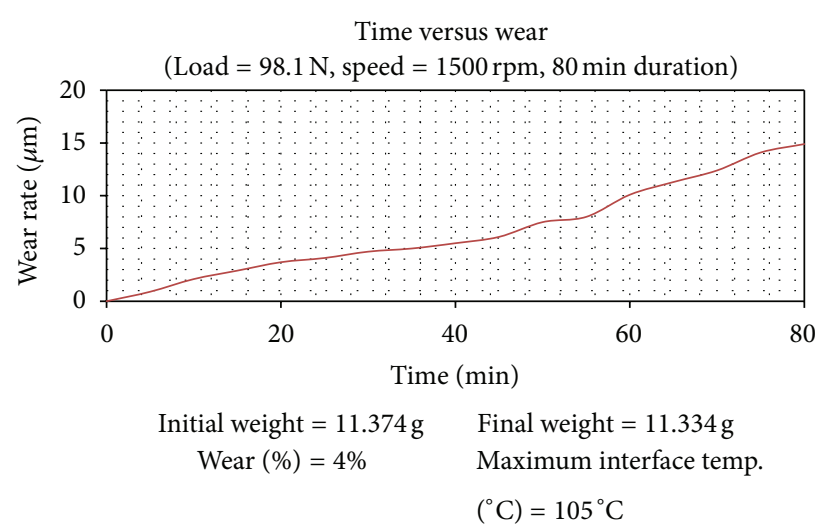

(b)

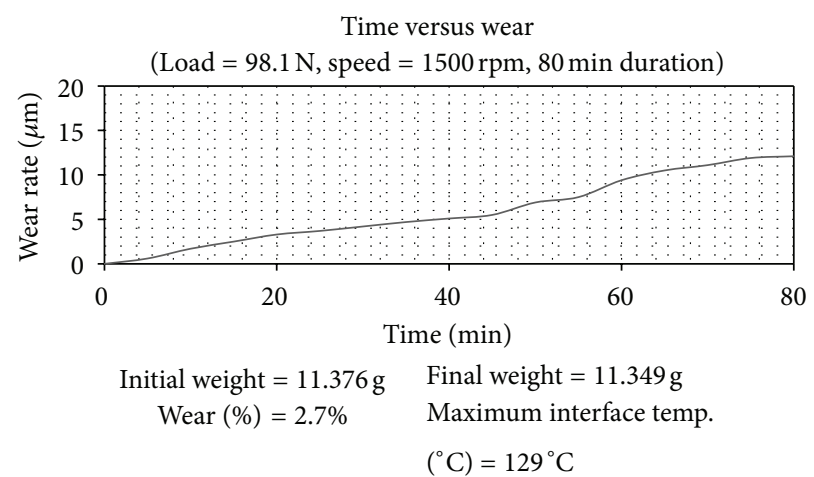

(d)

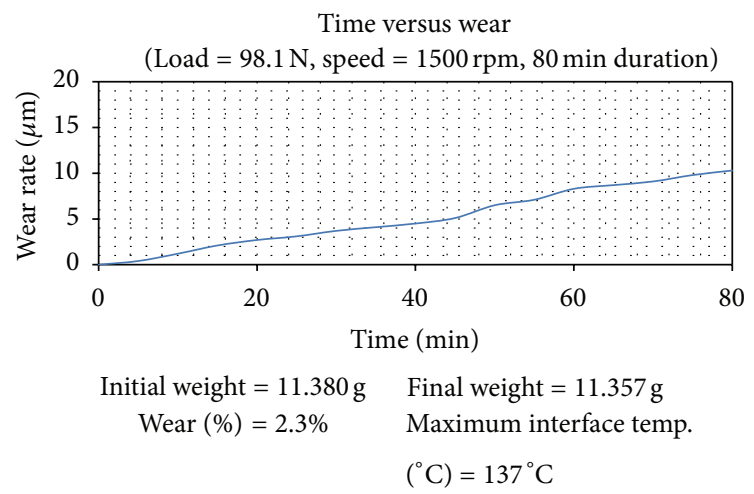

(e)

Figure 11: (a) Time versus wear for Na01. (b) Time versus wear for Na02. (c) Time versus wear for Na03. (d) Time versus wear for Na04. (e) Time versus wear for $\mathrm{Na} 05$.

(b) The load shall not be applied in shocks and the rate of increase.

(c) The test shall be carried up till the breaking up of the material occurs.

(4) Loss of Ignition. The sample of one gram is weighed accurately (to a third decimal place) in a previously ignited, cooled, and weighed silica crucible (without lid). The crucible containing the sample is introduced into the muffle furnace maintained at 800 to $850^{\circ} \mathrm{C}$ and soaked for two hours. Then the crucible shall be removed from the furnace, cooled in a dessicator, and weighed:

$$
\text { The percentage loss of weight }=100 \times \frac{\left(W_{2}-W_{3}\right)}{\left(W_{2}-W_{1}\right)},
$$

where $W_{1}$ : weight of empty crucible; g; $W_{2}$ : weight of crucible + sample, g; and $W_{3}$ : weight of crucible + sample (after ignition), g.

\section{Acknowledgment}

The authors express sincere thanks to Mr. B. Venugopal, CEO, Steadfast Friction Products, Ambattur SIDCO Industrial 


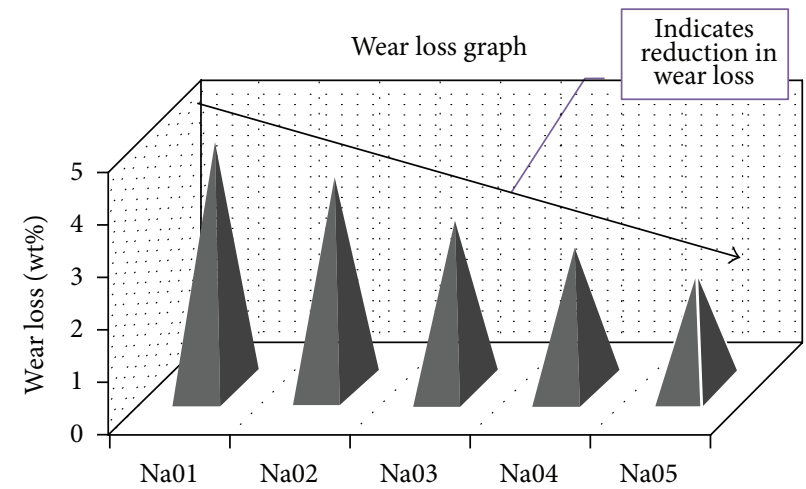

Figure 12: Wear loss by wt $\%$ of the various compositions.

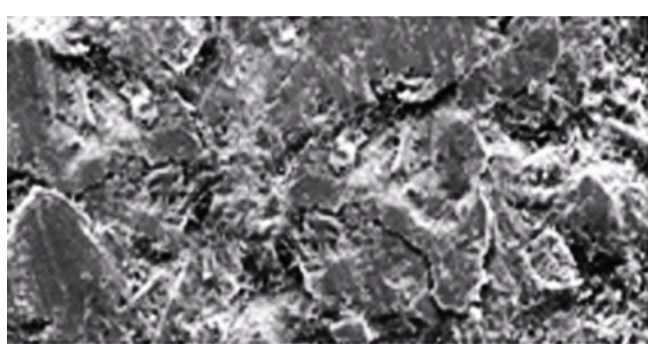

$10 \mu \mathrm{m} \quad \mathrm{EHT}=10.00 \mathrm{~W} \quad$ Signal A $=$ NA01 Date: $20 \mathrm{Jul} 2012$ $H \quad \mathrm{WD}=9.5 \mathrm{~mm} \quad \mathrm{Mag}=500 \mathrm{x} \quad$ Time: $10: 20$

(a)

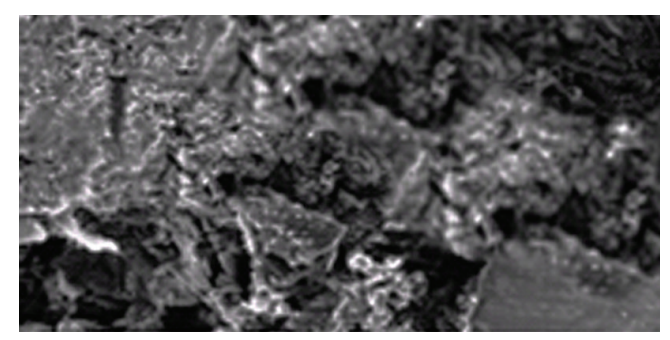

$10 \mu \mathrm{m} \quad \mathrm{EHT}=10.00 \mathrm{~W} \quad$ Signal A $=$ NA03 Date: $20 \mathrm{Jul} 2012$

$H \quad W D=9.5 \mathrm{~mm} \quad \mathrm{Mag}=500 \mathrm{x} \quad$ Time: $11: 08$

(c)



$10 \mu \mathrm{m} \quad \mathrm{EHT}=10.00 \mathrm{~W} \quad$ Signal A $=$ NA02 Date: 20 Jul 2012 $H \quad \mathrm{WD}=9.5 \mathrm{~mm} \quad \mathrm{Mag}=500 \mathrm{x} \quad$ Time: $10: 42$

(b)

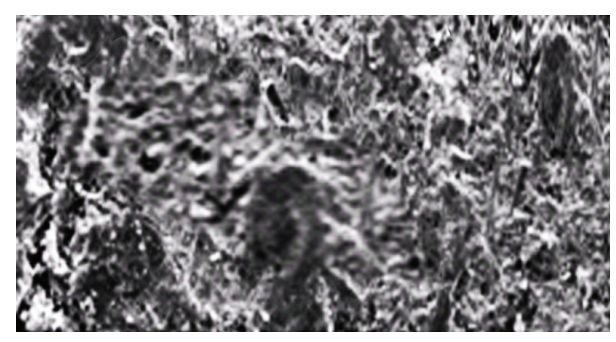

$10 \mu \mathrm{m} \quad$ EHT $=10.00 \mathrm{~W} \quad$ Signal A $=$ NA04 Date: 20 Jul 2012

$H \quad W D=9.5 \mathrm{~mm} \quad \mathrm{Mag}=500 \mathrm{x} \quad$ Time: $11: 15$

(d)



$10 \mu \mathrm{m} \quad \mathrm{EHT}=10.00 \mathrm{~W} \quad$ Signal A $=$ NA05 Date: 20 Jul 2012

$\mathrm{WD}=9.5 \mathrm{~mm} \quad \mathrm{Mag}=500 \mathrm{x} \quad$ Time: $11: 35$

(e)

FIGURE 13: (a) SEM of Na01 at 500x. (b) SEM of Na02 at 500x. (c) SEM of Na03 at 500x. (d) SEM of Na04 at 500x. (e) SEM of Na05 at 500x. 
estate, Chennai, for his kind help in the fabrication and testing of the composites.

\section{References}

[1] M. Kumar and J. Bijwe, "NAO friction materials with various metal powders: tribological evaluation on full-scale inertia dynamometer," Wear, vol. 269, no. 11-12, pp. 826-837, 2010.

[2] M. A. Sai Balaji and K. Kalaichelvan, "Thermal and fade aspects of a non asbestos semi metallic disc brakepad formulation with two different resins," Advanced Materials Research, vol. 622-623, pp. 1559-1563, 2013.

[3] G. Nicholson, Facts about Friction, Gedoran, Winchester, Virginia, 1995.

[4] J. Bijwe, "Composites as friction materials: recent developments in non-asbestos fiber reinforced friction materials-a review," Polymer Composites, vol. 18, no. 3, pp. 378-396, 1997.

[5] P. J. Blau, Compositions, Functions, and Testing of Friction Brake Materials and Their Additives, ORTN/TM-2001/64, 2000.

[6] J. H. Park, J. O. Chung, and H. R. Kim, "Friction characteristics of brake pads with aramid fiber and acrylic fiber," Industrial Lubrication and Tribology, vol. 62, no. 2, pp. 91-98, 2010.

[7] P. Gopal, L. R. Dharani, and F. D. Blum, "Load, speed and temperature sensitivities of a carbon-fiber-reinforced phenolic friction material,” Wear, vol. 181-183, no. 2, pp. 913-921, 1995.

[8] T. Kato and A. Magario, "Wear of aramid fiber reinforced brake pads: the role of aramid fibers," Tribology Transactions, vol. 37, no. 3, pp. 559-565, 1994.

[9] W. Österle, M. Griepentrog, T. Gross, and I. Urban, "Chemical and microstructural changes induced by friction and wear of brakes," Wear, vol. 250-251, no. 2, pp. 1469-1476, 2001.

[10] M. Eriksson, F. Bergman, and S. Jacobson, "On the nature of tribological contact in automotive brakes," Wear, vol. 252, no. 1-2, pp. 26-36, 2002.

[11] B. K. Satapathy and J. Bijwe, "Performance of friction materials based on variation in nature of organic fibres-part I: fade and recovery behaviour," Wear, vol. 257, no. 5-6, pp. 573-584, 2004.

[12] M. W. Shin, K. H. Cho, W. K. Lee, and H. Jang, "Tribological characteristics of binder resins for brake friction materials at elevated temperatures," Tribology Letters, vol. 38, no. 2, pp. 161$168,2010$. 

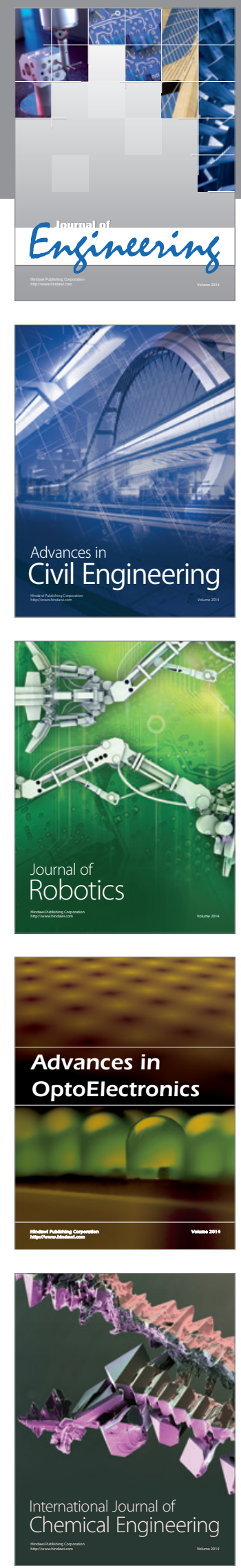

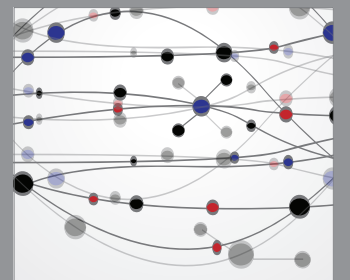

The Scientific World Journal
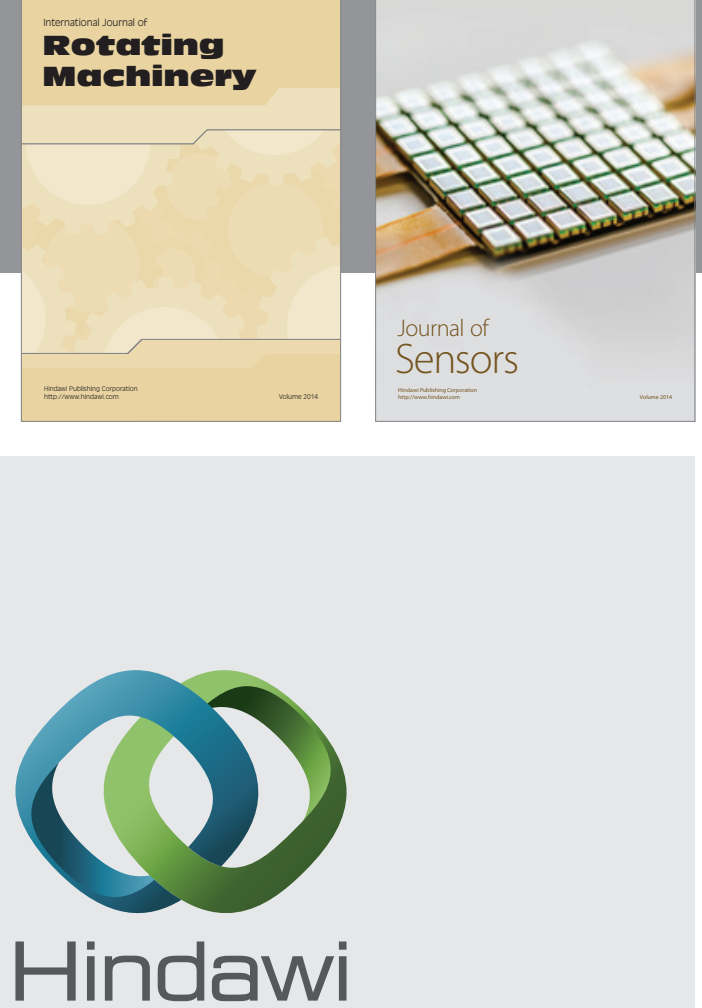

Submit your manuscripts at http://www.hindawi.com
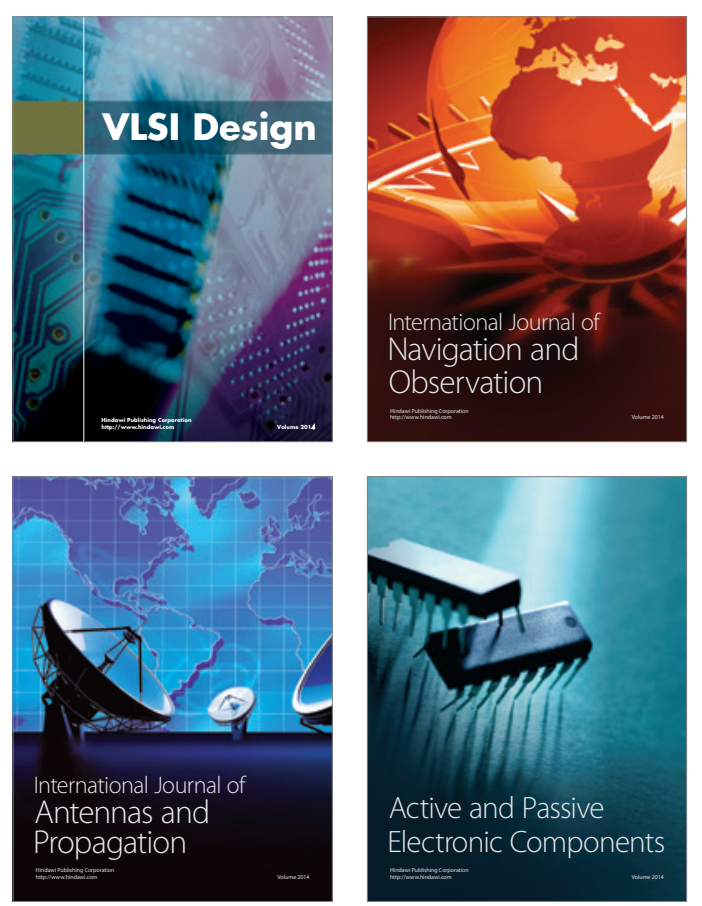
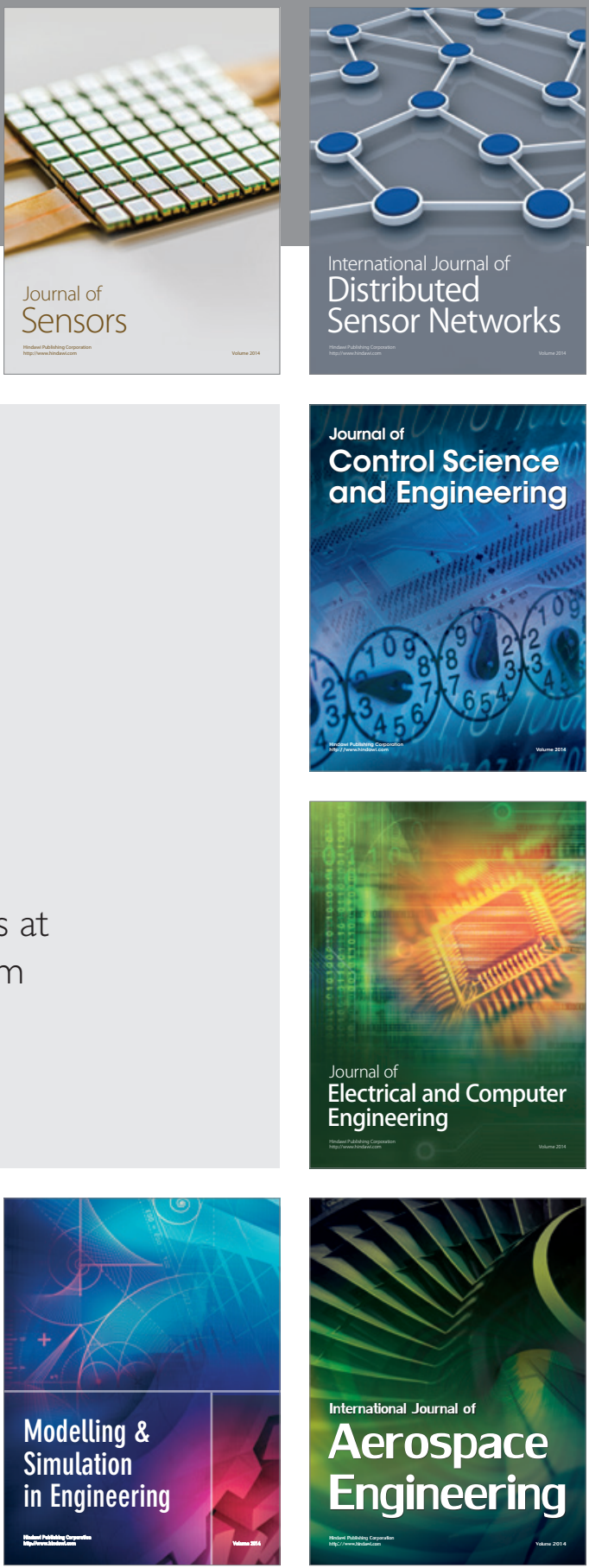

Journal of

Control Science

and Engineering
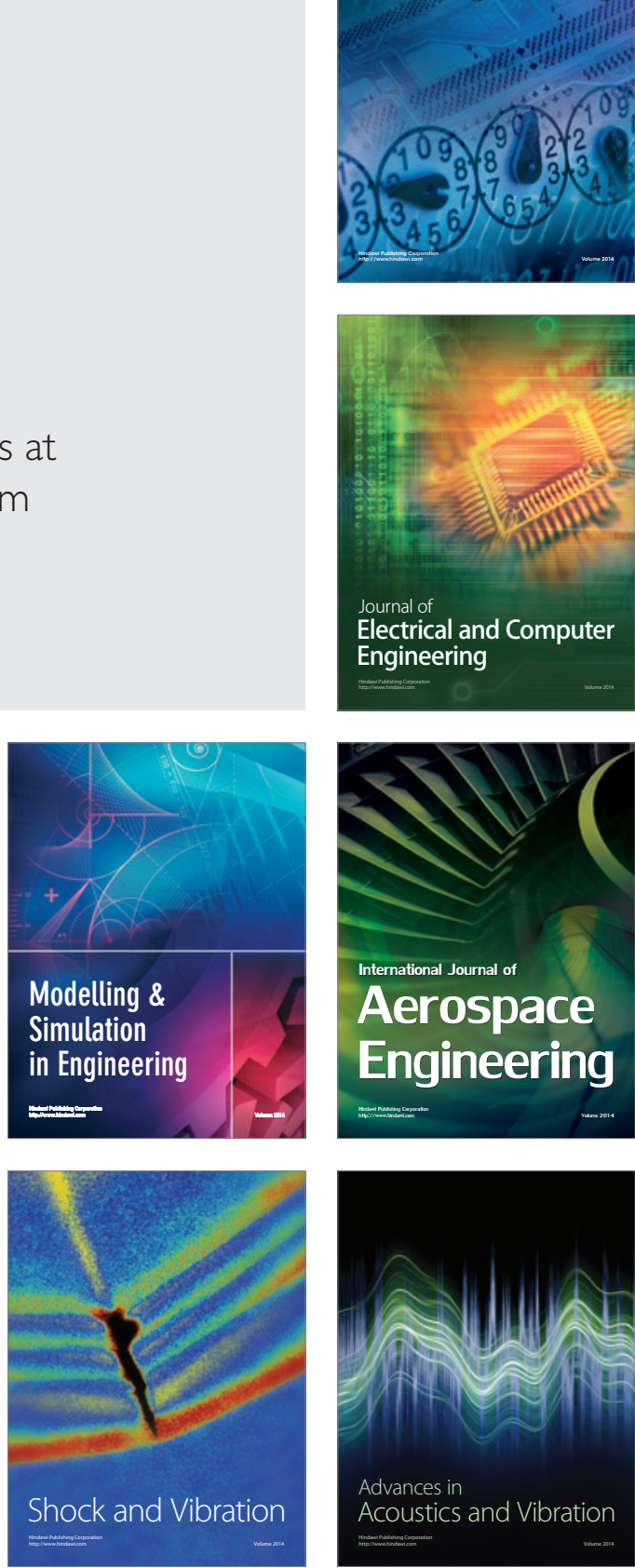